YOUNG DRIVERS

\title{
Youthfulness, inexperience, and sleep loss: the problems young drivers face and those they pose for us
}

\section{J A Groeger}

Injury Prevention 2006;12(Suppl I):i19-i24. doi: 10.1136/ip.2006.012070

Correspondence to: Professor J A Groeger, Department of Psychology \& Surrey Sleep Research Centre, University of Surrey, Guildford, UK; i.groeger@surrey.ac.uk

Accepted 24 April 2006
Young inexperienced drivers are more likely to be involved in road traffic crashes than drivers who are older and more experienced. This paper argues that neither age nor inexperience are, in and of themselves, sufficient explanations of the association between age, experience, and casualty rates. The aim here is to consider what it is about inexperienced young drivers in particular that may increase crash risk. Evidence is reviewed showing differential sleep loss among different teenage groups, which may relate to recently presented evidence that young teenagers are more crash involved than drivers in their early twenties. Potential acute and chronic effects of sleep loss among teenagers and young adults are described.
W hile the figures fluctuate, the "young driver problem" has been with us, in whichever country we live, for as long as substantial numbers of those in their teens have driven motor vehicles. ${ }^{1}$ This is, or should be, a sobering thought. So should the fact that there have been countless international initiatives focusing on training and education, testing and licensing, and/or restrictions on driving and traffic exposure. Many have been proposed, fewer trialled, still fewer fully evaluated, and most discarded without making it to the scientific literature, let alone becoming legislation or common practice. These thoughts might easily induce a state of discouraged pessimism, but they need not.

The fact is that the "young driver problem" is not simply one, but rather a variety of multifaceted problems, for which there is no single solution. There is surely little doubt that if a simple answer existed, it would have been discovered by some among the many excellent and determined researchers, practitioners, and politicians who have addressed the issue over previous decades. Instead, I believe there are a plethora of interventions which, if applied in concert, would reduce teen death and injury on our roads. None of these is "new" and none sufficient on its own-so what grounds are there for optimism? Firstly, our understanding of behavior, and the brain based systems on which it relies, has developed considerably. Secondly, our ability to monitor activity, and hence our ability to assess exposure, measure competence, and enforce restrictions has never been better.

This paper seeks to critically address the psychological and neuropsychological factors that underlie the "young driver problem", rather than to outline what might be the solution.

\section{AGE AND EXPERIENCE}

As pointed out quite some time ago by Ivan Brown, age, exposure, and experience are a "confounded nuisance" when it comes to attempting to understand driver behavior and crash involvement. ${ }^{2}$ Perhaps the most authoritative empirical resolution of this problem is over two decades old. Self reports from some 30000 UK drivers indicate that age (or rather youthfulness) and driving inexperience contribute independently to crash involvement. ${ }^{3}$ Thirty year old drivers with little driving experience are more likely to be crash involved than 30 year old drivers who have driven for several years. Twenty year old drivers with little driving experience have a higher crash likelihood than those who are 10 years older with a similar lack of driving experience. The catastrophically higher crash likelihood of teenage drivers stems from their lack of driving experience and their lack of age.

The implications for interventions that might reduce crash likelihood depend upon understanding why it is that both inexperience and youthfulness contribute to teenagers' crash involvement.

\section{WHY INEXPERIENCE?}

There have been some very challenging data reported in recent years regarding parent-child correlations in citation frequency and driving style. For example, children whose parents had been convicted of three or more traffic violations in the previous five years have been found to be some $40 \%$ more likely to commit traffic offences than children whose parents had clean driving records. ${ }^{4}$ Substantial correlations have also recently been reported between the driving behaviour of fathers and sons and between mothers and daughters, regardless of whether the parents were reckless or careful. $^{5}$

Despite the implication that there may be familial effects in traffic law compliance and safety, or whether any such relationship depends on nature or nurture, these findings do not indicate that any of us are born as good drivers. Driving is a skill we acquire through instruction and practice. The data available from longitudinal studies of learner drivers' performance during and after formal training show that skills develop as a power function of the hours of driving experience pupils gain. ${ }^{6}$

As can be seen from figure 1 , although not originally plotted in this way, cross sectional studies of teenage novice driver crash involvement appear to show a similar power function decline in crashes, whether plotted against distance driven or months of licensure. ${ }^{89}$ Although the fit to this function is far better in one case than the other, the fact that the power-law exponent is similar in both cases $(-0.3)$, suggests that both time for which a license has been held, as well as estimated driving distance, are approximations of some underlying measure of accumulated driving exposure. As will be shown later, using more specific indices of

Abbreviations: FARS, Fatality Analysis Reporting System; NHTS National Household Travel Survey; REM, rapid eye movement; SWS, slow wave sleep. 
- Crashes/10 000 drivers (Mayhew et al, 2003)

- Crashes/million km (Sagberg, 1998)

--- Power (crashes/million km (Sagberg, 1998))

- Power (crashes/10 000 drivers (Mayhew et al, 2003))

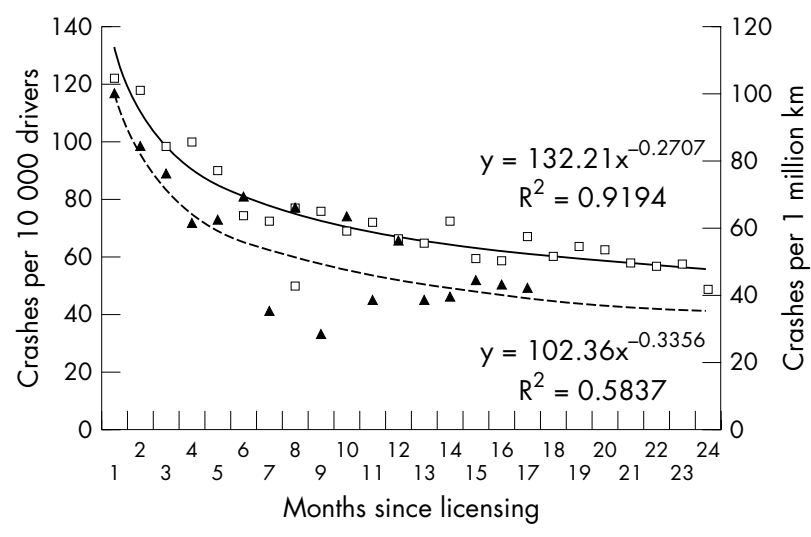

Figure 1 Young driver crash rates as a function of experience: time licensed and distance driven.

exposure can reveal quite unexpected differences in crash risk among young drivers. Overall, studies such as these demonstrate that whether performance or safety is used as an index, there is a strong power-law relationship between the total amount driven and the extent to which ability to drive safely changes. The fact that this power-law relationship holds has two implications: drivers improve far more when they have less experience than when they have more. This improvement continues inexorably, albeit almost undetectably, presumably until ability is compromised by a functional decline associated with ageing or disease.

The power-law relationship between practice and skill has been reported across a very wide range of human activities. There are a number of explanations of why this power-law relationship is observed, but that proposed by Gordon Logan is especially relevant here. ${ }^{10}$ According to Logan, when faced with any task or problem, the performers have two alternatives: rely on what they have done in similar situations in the past, or work out a new solution there and then. The former, memory based alternative is fast and relatively effortless, but depends on performers having appropriate memories (that is, experience). The latter algorithm based alternative is effortful, error prone, and depends on the performer identifying - presumably through analogy-what the problem is that needs to be solved. There are a number of implications of this account for understanding why "inexperience" is a problem.

The novice driver is forced to rely on the effortful, error prone process because there are few relevant memories to rely upon. It is only as experience is amassed that reliance on memories of previously successful solutions becomes a viable alternative, and only when considerable experience has been gained that the memory based process is relied upon. The result is that for the experienced driver, performance becomes less effortful, which among other things means less prone to disruption by distraction, and less variable. By contrast, novice driver performance is more demanding, more prone to distraction, and relatively inconsistent.

As has been argued previously, driving is a highly complex task (or combination of more or less simultaneous tasks). ${ }^{11}$ Some of the tasks that drivers perform are relatively predictable and invariant (for example, using the windshield wipers or changing gear in a manual shift car). Some are inherently unpredictable and highly variable (for example, the likely response of another motorist to a given circumstance). Performers require more practice to become proficient at complex tasks than to reach a similar level of skill on simple tasks. One reason might be that the memories required to sustain performance of simple tasks contain less extensive information about the circumstances in which they apply than those memories which support the performance of complex tasks (for example, they may need to contain information about a range of simpler tasks). From this it would follow that more task experience would be required to build up enough memories to sustain performance of a complex task. Thus, in order to drive competently under a desired condition, the novice driver who wishes to drive under a broader range of traffic conditions would actually need more experience of more traffic conditions than would the novice driver who wishes to drive under less variable traffic conditions.

It is important to emphasize a key implication of this analysis of why "inexperience" is a problem-that it is a lack of driving experience, not a lack of traffic experience, that is important. People need to actually perform the activity repeatedly in order to improve their performance. Being taught about it second hand, watching it, or simply getting older does not yield the same-if any-improvement.

\section{WHY YOUTHFULNESS?}

The rationale for why youthfulness predicts crash involvement is more speculative. Why should a 17 year old be a less skillful driver than a 19 year old; or a 25 year old more skillful than his younger peers? Before offering a number of tentative suggestions, and herding a few sacred cows, it should be noted that as used here, the term "skillful" includes all of the skills drivers require (the ability to judge and predict the behavior of others as well as the ability to control the vehicle, respond quickly, accurately, etc).

When I first began my research of young drivers, I was uncomfortable with the caricature of the young driver as a wilful, overly optimistic, male, hormone crazed exhibitionist. This is perhaps an unfair caricature of the views of those who stress the problem behaviors or problem personalities of the young. ${ }^{12}$ However, 20 odd years on I am no more drawn to this stereotype as an explanation of the overinvolvement of young, inexperienced drivers in traffic crashes. One of the implications of such views seems to be that teenage drivers are more homogeneous than those 10 years older-a view that would be difficult to substantiate.

Furthermore, although adolescence is, quite literally, formative in terms of personality, longitudinal studies of personality show little change between the late teens and early twenties. ${ }^{13-15}$ Table 1 , derived from a recent review and meta-analysis of studies of personality change, ${ }^{16}$ shows that the changes that do occur do not support the supposition that personality factors underpin the differences in safety. Young teenagers become more socially independent, self-confident, and more emotionally stable as they age. Young adults become still more independent and self-confident, still more emotionally stable, more positive, gregarious, and more open to experience as they leave their early twenties. That is, these results imply that the very unsafe youngest drivers are actually less self-confident, and less interested in having new experiences than their older and safer driving peers.

Even if there were evidence of personality change on a scale similar to that observed with crash involvement, an unequivocal link between personality and crash involvement or driver behavior has proved more than elusive in almost a century of research on the topic. ${ }^{11}{ }^{17}$

Increases in social independence and confidence that occur in the late teens and early twenties may be reflected in "optimism bias" or exaggeration of abilities. Much of this 
Table 1 Changes in personality among teenagers and young adults (after Roberts et al, $2006^{16}$ )

\begin{tabular}{|c|c|c|c|c|c|c|}
\hline \multirow[b]{2}{*}{ Traits } & \multicolumn{3}{|c|}{ Age $10-17$ years } & \multicolumn{3}{|c|}{ Age $18-22$ years } \\
\hline & $\begin{array}{l}\text { Sample } \\
\text { size }\end{array}$ & $\begin{array}{l}\text { Effect } \\
\text { size }\end{array}$ & $\begin{array}{l}\text { Confidence } \\
\text { intervals }\end{array}$ & $\begin{array}{l}\text { Sample } \\
\text { size }\end{array}$ & $\begin{array}{l}\text { Effect } \\
\text { size }\end{array}$ & $\begin{array}{l}\text { Confidence } \\
\text { intervals }\end{array}$ \\
\hline Social vitality & 6132 & 0.11 & -0.06 to 0.27 & 3929 & $0.06^{*}$ & 0.01 to 0.10 \\
\hline Social dominance & 1700 & $0.20^{*}$ & 0.01 to -0.39 & 1655 & $0.41^{*}$ & 0.13 to -0.69 \\
\hline Agreeableness & 4378 & 0.01 & -0.09 to 0.11 & 2239 & 0.05 & -0.08 to 0.18 \\
\hline Conscientiousness & 7506 & 0.03 & -0.09 to 0.14 & 5226 & 0.04 & -0.18 to 0.11 \\
\hline Emotional stability & 10,557 & $0.16^{*}$ & 0.09 to 0.23 & 3621 & $0.12^{*}$ & 0.004 to 0.24 \\
\hline Openness & 2911 & 0.23 & 0.00 to 0.48 & 3998 & $0.37^{*}$ & 0.18 to 0.56 \\
\hline
\end{tabular}

research is based on rather questionable methodology in which people are asked to compare themselves with an "average" performer. Using a different approach we have shown that older experienced drivers, rather than younger inexperienced drivers, have a far more positive view of their driving ability than is warranted..$^{18}$ A further study, to my knowledge the only one that tests the hypothesis that there is a developmental trend in judgments of one's own ability, shows that learner drivers and newly qualified drivers appear to have a very well calibrated view of their own ability when asked to compare their ability with a driver more similar to themselves (that is, a newly qualified driver). Figure 2, replotted from my book, shows that beginning learner drivers consider themselves far worse than a newly qualified driver, a tendency which decreases as drivers themselves come closer, and eventually succeed in, being qualified to drive alone. The drivers in this study considered themselves no better than novices even after several months of independent driving.

So if it is not personality change or unwarranted optimism, what could these highly specific age related changes be that render a teenager less safe than a 25 year old? While not denying that social and lifestyle factors contribute substantially, I wish to draw attention to a more pervasive and highly specific age related change which is rarely seen as a particular contributor to the young drivers' overinvolvement in traffic crashes-the exception being the pioneering work by Mary Carskadon and colleagues. ${ }^{19}$

\section{SLEEP RESTRICTION AMONG TEENAGERS AND YOUNG ADULTS}

Changes in sleep habits and, perhaps, sleep architecture accompany the transition from teenager to young adult. ${ }^{20} 21$

Figure 3 presents data from approximately 200 teenagers, surveyed every two years across a 10 year period. ${ }^{22}$ While the

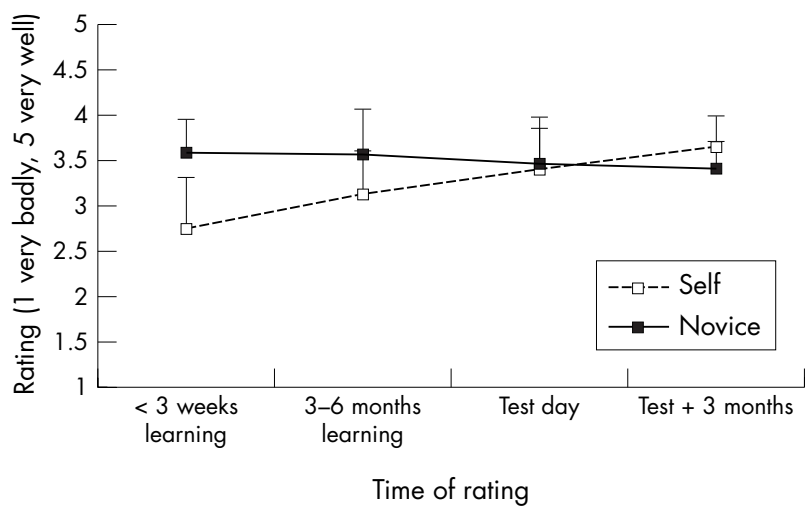

Figure 2 Self/novice ability comparisons among British teenage learner drivers. majority of respondents claim that they need more sleep than they typically have, by the middle teens almost $70 \%$ of children report needing more sleep. This figure declines to about $50 \%$ of the sample for these individuals when they reach their early twenties. Reported time in bed declines systematically over the teenage years, but the reported time in bed over the weekend remains reliably higher, and declines less sharply. This pattern is consistent with respondents having to make up for lost sleep at the weekend when there is presumably greater opportunity to do so.

A recent survey of sleep patterns among a representative sample of the population of the UK confirms these results. ${ }^{21}$ Figure 4 shows data extracted relating to those in their midteens to mid-twenties $(n=173)$. The discontinuity in reported sleep times between those aged 16-18 and 19 and older is immediately apparent. There is, however, an increase in feeling refreshed on waking.

Sleep loss among teenagers appears to have profound effects. Wolfson and Carskadon (1998) carried out an extensive cross sectional study of US high school students. ${ }^{23}$ Their data show that reported average daily sleep reduces with age, by some 40-50 minutes across 13-19 year olds, with some of this loss being recovered at weekends. This sleep loss is manifested in gradually later bed times, but more or less stable rise times across the age range. Those who had far later bed times at weekends, or who slept much less than average, had lower school grades, reported increased daytime sleepiness, depressive mood, and sleep/wake behavior problems. The same authors have also presented a compelling review of the educational effects of sleep loss among

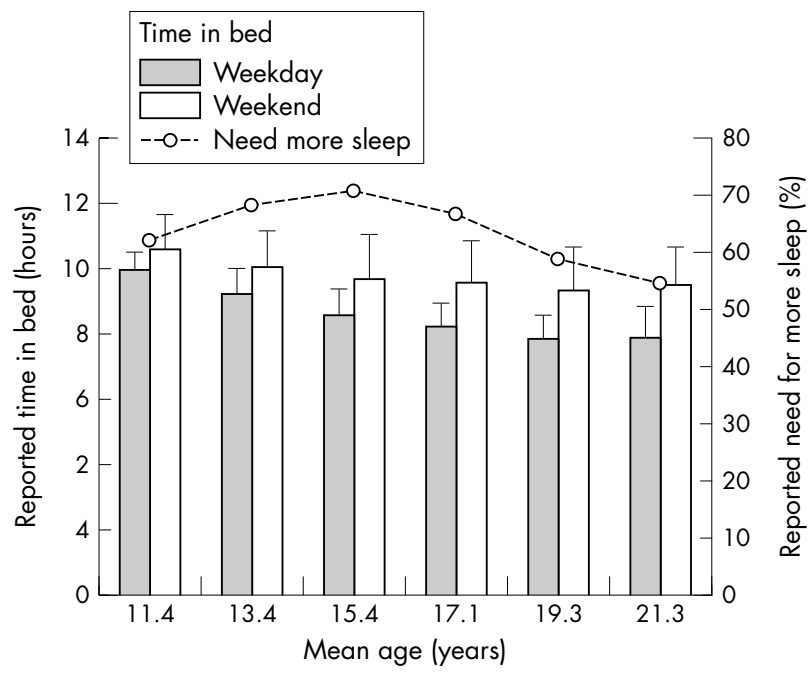

Figure 3 A longitudinal study of reported sleep and sleep need among those aged 11-21 years (after Strauch and Meier, 1988 ${ }^{22}$ ). 


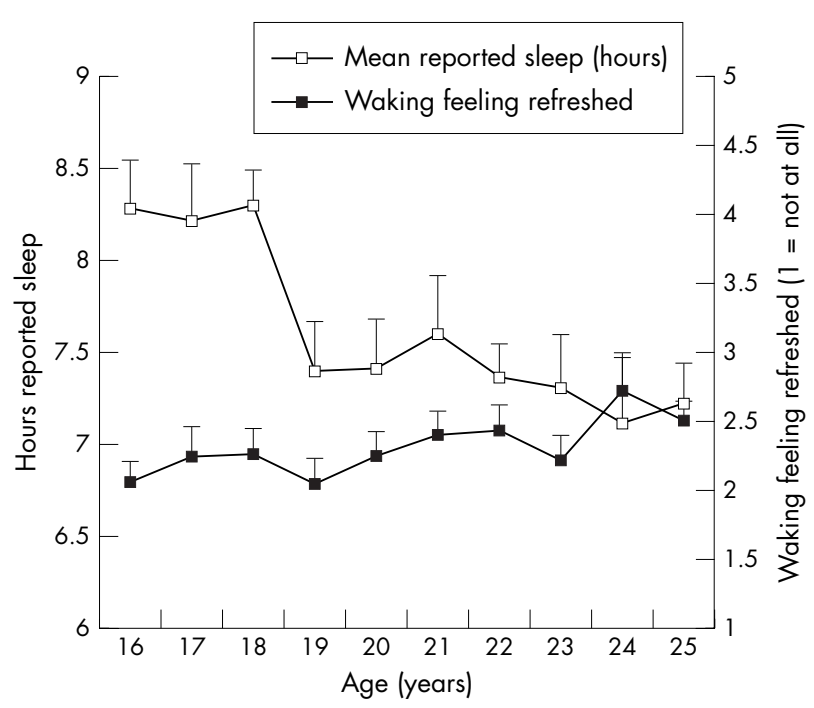

Figure 4 Reported sleep and waking feeling refreshed among young British adults (mean, SEM).

adolescents. ${ }^{24}$ Recently, again on the basis of a high school survey, it has been shown that adolescents who reported going to bed later at weekends (and much later than their weekday bed times) and higher levels of sleep problems also reported significantly higher levels of risk taking behaviors. ${ }^{25}$ Students' delayed weekend bed times were also related to academic performance in this sample.

Underlying plots of crash rates by distance driven or license holding, such as those presented in figure 1 earlier, are profound effects of the circumstances under which this experience is gained. Regrettably, matters are still more complicated than even these exposure indices suggest. Thus far it has been implied that distance driven is what is important in assessing relative risk, rather than the circumstances or conditions under which driving takes place. However, half of all teenage crashes take place at night, but just $20 \%$ of teenage driving occurs at night. ${ }^{26}$ Australian data show that crash rates, per million miles driven, are also two and a half times higher during hours of darkness. ${ }^{27}$ Furthermore, $60 \%$ of young driver deaths occur at night, with the majority of these being on weekend nights (37\%). Importantly, this percentage of fatalities is three times that for daytime on weekends, whereas the percentage of young drivers who die in daytime crashes and night-time crashes during the week is similar (25\% and $24 \%$ respectively). ${ }^{27}$ Similarly, a comparison across several European countries (UK, Netherlands, France, Belgium) has shown that young drivers are overrepresented in night-time crashes (all), particularly weekend night-time crashes (UK), those involving speed (France, Netherlands), on curves (Netherlands), and single vehicle crashes (all). ${ }^{28}$

This study also suggests that passengers are a particular problem for the young driver. This finding is corroborated and extended by a more recent US study, which shows that among 16 and 17 year old drivers, death rates increase systematically as a function of the number of passengers carried, but the crash rates for older motorists are similar irrespective of the numbers of passengers carried. ${ }^{29}$ It may be that this passenger effect partly underlies the increased death rate of young people on weekend nights. Young drivers not only kill themselves, they also kill other road users more frequently. ${ }^{30}$

These studies suggest that the young driver is at particular risk at night, but do not distinguish sufficiently between drivers to support the view that, within young drivers, there is a differential susceptibility to crashes at night.

Sweeney and colleagues have recently presented a compelling re-analysis of 2001/02 Fatality Analysis Reporting System (FARS) traffic crash data. ${ }^{31}$ In their analysis, FARS data are weighted by information from the National Household Travel Survey (NHTS). The NHTS includes detailed information on daily and long distance travel, and estimates the number of drivers of particular ages on the road during a given hour across the day. Figure 5 replots these data, using two hour overnight periods. As might be expected, fatigue related crash risk is highest in the early hours of the day. Remarkably, however, taking account of the driving patterns of drivers within an age cohort reveals far higher risk of crashes classed as fatigue related among teenage drivers than among drivers aged 19-24. Both groups are at considerably higher risk of fatigue related crashes than all other age groups, even beyond the age ranges plotted in figure 5 . These findings are striking in light of the changing sleep patterns for these age ranges reviewed above. Obviously, since this is simply an age based contrast, the relatively lower crash risk of the 19-24 year old drivers may reflect both age and greater driving experience. Despite this caveat, it is tempting to interpret the data in terms of a differential susceptibility to the effects of sleep loss. It is possible the increased crash involvement of these younger drivers reflects both acute (that is, specific to a particular occasion) and chronic or enduring effects of the difference between sleep obtained and that required/desired.

The acute effects of sleep loss reflect the relatively temporary effects of fatigue to which we are all prone, irrespective of age. These will include reductions in capacity to process information, decreases in sustained attention, less accurate motor control, increased reaction time, etc. It is worth noting that these effects may well be more prevalent when the performer is less experienced. In addition, albeit in a study of more experienced drivers, sleep restriction has been shown to interact with susceptibility to the effects of alcohol. $^{32} 33$ These studies showed that very low doses of alcohol (less than $40 \mathrm{mg} / 100 \mathrm{ml}$ ) impair performance more among those suffering moderate levels of sleep deprivation than among those who are not. This may also be true for the effects of other drugs, although I am unaware of empirical evidence for this. It is worth noting here the findings of Dawson and others who have shown that as much impairment in driving ability occurs among sober drivers who have

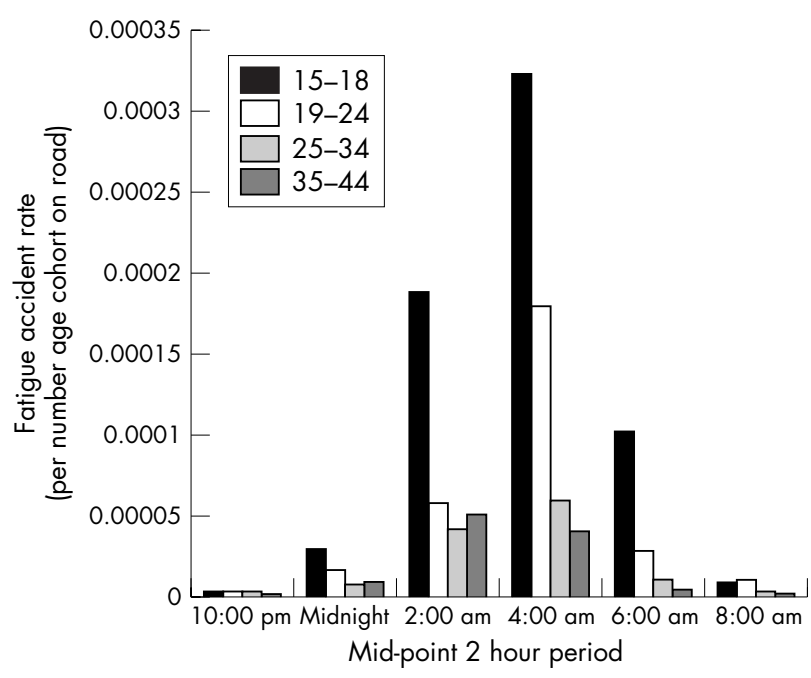

Figure 5 US fatigue crash rate as a function of time of day and driver age from April 2001 to May 2002 (after Sweeney et al, 2003 ${ }^{31}$ ). 
not slept in 24 hours as in drivers who have had normal sleep but have ingested $100 \mathrm{mg}$ of alcohol. ${ }^{34} 35$

The possibility that there may be "chronic" effects of sleep loss in teenagers is an even more tantalizing possibility. Not only does sleep duration change as a function of age, but so too does the structure of that sleep. It is very noteworthy that sleep structure changes markedly across adolescence and early adulthood, with, among other changes, a considerable reduction in the amount of slow wave sleep (SWS). ${ }^{30}{ }^{35}$ The amount of rapid eye movement (REM) sleep may also be reduced among teenagers. Delayed sleep phase syndrome, the tendency towards later bed times in older teenagers, together with the requirement to rise early to begin the school day at traditional times, will reduce sleep duration. ${ }^{37}$ However, the delayed sleep time will also cause an increased requirement for SWS, with a consequent reduction in the time available for REM. Thus the two major constituents of sleep will change considerably within and between teenagers.

Although we are still some way short of a functional account of the contribution different sleep stages make to waking performance, recent evidence indicates that newly acquired procedural skills may be consolidated during sleep, particularly during SWS/REM. ${ }^{38}{ }^{39}$ There is also growing evidence for a contribution of SWS to the consolidation of the learning of factual, rule based, semantic (that is, "declarative") knowledge, ${ }^{40}$ as well as to the consolidation of emotionally laden "episodic" events. ${ }^{41}$ Thus far, the tasks used to explore the relationships between types of memory and sleep structure are relatively simple and unlike everyday tasks, but if similar relationships hold with the learning of complex tasks such as driving, the implications are indeed profound. Sleep loss in teenagers learning to drive, or in the early stages of their careers as independent drivers, may not be able to acquire and consolidate the declarative, procedural, and episodic knowledge on which safe driving depends. At this stage, the suggestion that there may be chronic as well as acute effects of sleep loss that particularly affect teenage drivers is no more than a hypothesis, but it is one worthy of very careful exploration.

\section{CONCLUSION}

Youthfulness and lack of driving experience are clearly associated with lack of traffic safety, but this describes, rather than explains, what is a profoundly serious problem. The age related "explanations" that have been offered, such as age related changes in personality, sensation seeking, confidence, risk taking, and so on, rarely show the extent of change over the critical ages to provide an adequate explanation of why the young are involved in proportionally more crashes than their older peers. A more plausible account is offered, this paper has argued, by the teen driver's lack of traffic experience, because of factors such as restricted learning opportunities and failure to transfer learning to novel circumstances. This paper has also sought to draw attention to a rarely addressed age related issue-sleep restriction-which may have both acute and chronic effects on teen driving performance. It is argued that social and lifestyle changes may reduce sleep opportunities. Somehow the teenager must juggle the pressures of attending school, engage in a developing night-time social life, and often work evenings or early mornings in order to sustain this developing lifestyle. Furthermore, competing demands on weekend time that might otherwise be used for recuperation are less available. While there are many important biological changes that occur in teenagers, differential susceptibility to sleep restriction is one that may have profound implications for safety-not only in traffic but elsewhere as well. Lifestyle and biology may be on a collision course in the teenage years.

\section{About the author}

John Groeger is a Professor of Cognitive Psychology in the School of Human Sciences and a founder member of Surrey Sleep Research Centre at the University of Surrey, Guilford. $\mathrm{He}$ is a former Chair of the Cognitive Section of the British Psychological Society and President of the Traffic and Transport Division of the International Association of Applied Psychology. He is the author of Understanding Driving: Applying cognitive psychology to a complex everyday task (Psychology Press, 2000). With Talib Rothengatter of the University of Groningen (Netherlands), Dr Groeger launched and now co-edits Transportation Research: Traffic and Transport Psychology (Elsevier Science). He received an MA from University College Cork and a PhD from Queen's University Belfast.

\section{ACKNOWLEDGEMENT}

I am very grateful to Derk-Jan Dijk (Director, Surrey Sleep Research Centre), and Danielle Rodriguez, a graduate student of mine, whose willingness to share their knowledge of the sleep literature has been a constant encouragement to me to apply this in the driving domain. This paper was first presented as part of the first Expert Panel meeting of the Youthful Driver Research Initiative, a collaborative research program between the Center for Injury Research and Prevention (http://www.chop.edu/injury) at the Children's Hospital of Philadelphia (CHOP) (http://www.chop.edu) and State Farm Insurance Companies ${ }^{\circledR}$ (State Farm) (http://www.statefarm.com). The views presented in this paper are those of the author(s) and are not necessarily the views of CHOP or State Farm.

\section{REFERENCES}

1 Phebo L, Dellinger AM. Young driver involvement in fatal motor vehicle crashes and trends in risk behaviors, United States, 1988-95. Inj Prev 1998;4:284-7

2 Brown ID. Exposure and Experience Are a Confounded Nuisance in Research on Driver Behavior. Accid Anal Prev 1982:14:345-52.

3 Maycock G, Lockwood CR, Lester J. The accident liability of car drivers, TRL Research Report 315. Crowthorne, UK: Transport Research Laboratory, 1991.

4 Ferguson SA, Williams AF, Chapline JF, et al. Relationship of parent driving records to the driving records of their children. Accid Anal Prev 2001;33:229-34.

5 Taubman-Ben-Ari O, Mikulincer M, Gillath O. From Parents to Children Similarity in parents and offspring driving styles. Transportation Research Part F 2005;8:19-29.

6 Groeger JA, Clegg BA. Practice and instruction when learning to drive, Road Research Report No 14. London: HMSO, 2000.

7 Groeger JA, Brady SJ. Differential effects of formal and practice and instruction when learning to drive, Road Research Report No 42. London: HMSO, 2004.

8 Sagberg F. Month by month changes in accident risk. Paper presented at the International Association of Applied Psychology, San Fransisco, 9-14 August, 1998.

9 Mayhew DR, Simpson HM, Pak A. Changes in collision rates among novice drivers during the first months of driving. Accid Anal Prev 2003;35:683-91.

10 Logan GD. Toward an instance theory of automatization. Psychol Rev 1988:95:492-527.

11 Groeger JA. Understanding driving: applying cognitive psychology to a complex everyday task. Hove, UK: Psychology Press, 2000.

12 Jessor R. Problem-behavior theory, psychosocial development, and adolescent problem drinking. Br J Addict 1987;82:331-42.

13 McCrae RR, Costa PT, Terracciano A, et al. Personality trait development from age 12 to age 18: Longitudinal, cross-sectional, and cross-cultural analyses. J Pers Soc Psychol 2002;83:1456-68.

14 Roberts BW, Caspi A, Moffitt TE. The kids are alright: Growth and stability in personality development from adolescence to adulthood. J Pers Soc Psychol 2001;81:670-83.

15 Robins RW, Fraley RC, Roberts BW, et al. A longitudinal study of personality change in young adulthood. J Pers 2001;69:617-40.

16 Roberts BW, Walton KE, Viechtbauer W. Patterns of mean-level change in personality traits across the life course: A meta-analysis of longitudinal studies. Psychol Bull 2006;132:1-25.

17 Barjonet P. Transport psychology and transport in Europe: A general overview. In: Rothengatter JA, Carbonell-Vaya E (eds). Traffic and transportation psychology: theory and application. Pergamon: Oxford, 1997: 137-46.

18 Groeger JA, Grande GE. Self-preserving assessments of skill? Br J Psychol 1996;87:61-79. 
19 Carskadon MA, Harvey K, Dement WC. Sleep loss in young adolescents. Sleep 1981;4:299-312.

20 Ohayon MM, Carskadon MA, Guilleminault C, et al. Meta-analysis of quantitative sleep parameters from childhood to old age in healthy individuals: Developing normative sleep values across the human lifespan. Sleep 2004;27:1255-73.

21 Groeger JA, Zijlstra FRH, Dijk DJ. Sleep quantity, sleep difficulties and thei perceived consequences in a representative sample of some 2000 British adults. J Sleep Res 2004;13:359-71.

22 Strauch I, Meier B. Sleep need in adolescents - a longitudinal approach. Sleep 1988; 11:378-86.

23 Wolfson AR, Carskadon MA. Sleep schedules and daytime functioning in adolescents. Child Dev 1998:69:875-87.

24 O'Brien EM, Mindell JA. Sleep and risk-taking behavior in adolescents. Behav Sleep Med 2005;3:113-33.

25 Wolfson AR, Carskadon MA. Understanding adolescent's sleep patterns and school performance: a critical appraisal. Sleep Med Rev 2003;7:491-506.

26 Williams AF. Nighttime driving and fatal crash involvement of teenagers. Accid Anal Prev 1985;17:1-5.

27 Australian Transport Safety Bureau. Road safety in Australia, A Publication Commemorating World Health Day 2004, Commonwealth of Australia, Canberra, 2004.

28 Twisk DAM. Young driver accidents in Europe: characteristic young driver accidents in the member states of the EU. Leidschendam, Netherlands: SWOV Institute for Road Safety Research, 1994.

29 Chen L-H, Baker SP, Braver ER, et al. Carrying passengers as a risk factor for crashes fatal to 16-17 year old drivers. JAMA 2000;283:1578-82.

30 United States Dept of Transportation, National Highway Traffic Safety Administration. Traffic safety facts 2003: young drivers. Washington, DC: NHTSA, 2004.
31 Sweeney M, Giesbrecht L, Bose J. Using data from the 2001

National Household Travel Survey to evaluate accident risk. Paper presented at 30th Annual International Traffic Records Forum, Nashville, July 25-27, 2004.

32 Horne JA, Reyner LA, Barrett PR. Driving impairment due to sleepiness is exacerbated by low alcohol intake. Occup Environ Med 2003;60:689-92.

33 Barrett PR, Horne JA, Reyner LA. Sleepiness combined with low alcohol intake in women drivers: Greater impairment but better perception than men? Sleep 2004;27: 1057-62.

34 Lamond N, Dawson D. Quantifying the performance impairment associated with fatigue. J Sleep Res 1999;8:255-62.

35 Maruff $P$, Falleti MG, Collie A, et al. Fatigue-related impairment in the speed, accuracy and variability of psychomotor performance: comparison with blood alcohol levels. J Sleep Res 2005;14:21-7.

36 Landolt H-P, Dijk D-J, Achermann P, et al. Effect of age on the sleep EEG: slow-wave activity and spindle frequency activity in young and middle-aged men. Brain Research 1996;738:205-12.

37 Jenni OG, Achermann P, Carskadon MA. Homeostatic sleep regulation in adolescents. Sleep 2005;28:1446-54.

38 Walker MP. A refined model of sleep and the time course of memory formation. Behav Brain Sci 2005;28:51-64, 64-104.

39 Groeger JA, Dijk DJ. Consolidating consolidation? Sleep stages, memory systems, and procedures. Behav Brain Sci 2005;28:73-4.

40 Gais S, Born J. Declarative memory consolidation: Mechanisms acting during human sleep. Learn Mem 2004;11:679-85.

41 Wagner U, Degirmenci M, Drosopoulos S, et al. Effects of cortisol suppression on sleep-associated consolidation of neutral and emotional memory. Biol Psychiatry 2005;58:885-93. 